\title{
Frank Morgan Appointed Notices Editor-in-Chief
}

\author{
Elaine Kehoe
}

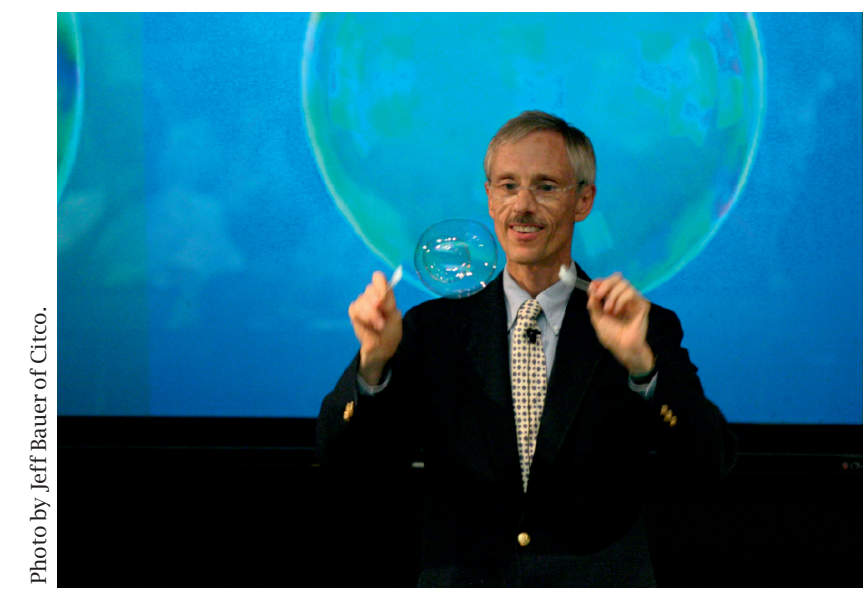

In 2000 Morgan et al. proved that the standard double soap bubble is more efficient than any other possibility, such as the bubble inside a bubble pictured here.

FRANK MORGAN of Williams College will begin a three-year term as editor in chief of the Notices starting with the January 2016 issue. He succeeds Steven G. Krantz of Washington University in St. Louis, who has been editor since 2010.

Frank Morgan attended the Massachusetts Institute of Technology and Princeton University, from which he received his $\mathrm{PhD}$ under Fred Almgren in minimal surfaces. In 2000, working with colleagues and students, he proved the Double Bubble Conjecture, which states that the standard double soap bubble-a little sphere and a big sphere, with the surface between them -is the least-area way to enclose and separate two given volumes of air.

Morgan has taught for ten years at MIT and now for twenty-eight at Williams, where he founded

Elaine Kehoe is a Notices contributing writer. Her email address is elainekehoe@cox. net.

For permission to reprint this article, please contact: reprint-permission@ams.org.

DOI: http://dx.doi.org/10.1090/noti1293 the SMALL undergraduate research project. Last fall he taught developmental algebra at Berkshire Community College. He has served on the AMS Council, and as AMS vice president he did an eightweek Asian speaking tour and founded the AMS Graduate Student Blog.

Morgan has published two hundred papers and six books, including Geometric Measure Theory, Calculus, and The Math Chat Book, based on his live call-in TV show and newspaper column. He has given over eight hundred talks at venues ranging from high schools to research seminars. He has a busy website at math. wi 11 iams . edu/morgan.

But what qualifications does Morgan have to be an editor? Well, he was editor of the Raub Junior High School yearbook, Warrior.

Morgan loves the Notices and its potential. "I feel very close to the wide audience of Notices readers and promise with their help to make it as interesting as possible," he says.

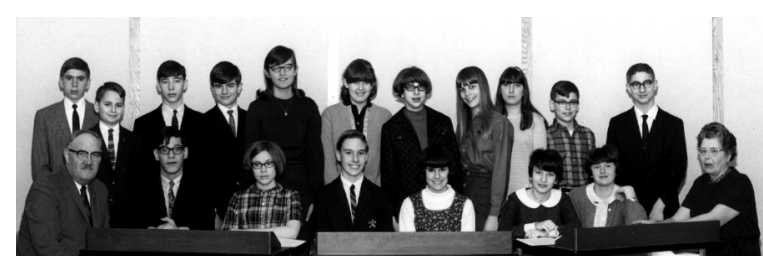

Editor Morgan, seated front center, with the staff of his junior high school yearbook,

Warrior.

"I hope that they'll like the new Graduate Student section and entertaining Back Page along with the latest math, participate in the new Commentary feature at the Notices homepage, submit all kinds of interesting articles, and enjoy Notices with friends." He invites wide-ranging suggestions for articles, authors, innovations, consultants, and editors, including self-nominations, at fmorgan@ wi 11 iams. edu. 